\title{
From subsistence to nuisance?: Rice and the process of demographic transformation and adaptation in the village of East Laguna, Philippines
}

\author{
L. Ang \\ Fenner School of Environment and Society, Building 48, Daley Road, \\ The Australian National University, Acton ACT 0200, Canberra, Australia
}

\begin{abstract}
The Green Revolution and the wave of political reforms it inspired during the 1970s significantly contributed to increases in rice supply in the Philippines, where at the time, modernisation logically established agricultural intensification as a means to rice stability for the country. This period of growth in Philippine history would, on face-value, seem to demonstrate Ester Boserup's classic expectation that population pressures lead to agricultural innovation and intensification so as to elevate food production. Three decades have since passed, and it becomes of great interest to explore and qualify how Boserup's model stands in the face of modernisation, and in turn, how population and intensification are ultimately shaping rural lives in the Philippines. This essay will take as its case study the rice village of East Laguna, a "rural" community located south of Laguna de Bay, the country's largest lake. An examination of the village's demographic history as it has undergone transformation and adaptation indicates several limits to Boserupian modes of growth while at the same time emphasising the role of agency and practicality in determining smallholder outcomes in the face of socio-economic change.
\end{abstract}

\section{INTRODUCTION}

Rice maintains its status as the most important staple crop in the Philippines (Van der Eng 2004: 347). Its production delicately holds together the country's agricultural sector and is hence central to the overall well-being of the nation's growing rural population. The experience of the Green Revolution and the wave of political reforms it inspired during the 1970s significantly contributed to increases in rice supply in the Philippines, where at the time, modernisation logically established agricultural intensification as a means to rice stability for the country. This period of growth in Philippine history would, on face-value, seem to demonstrate Ester Boserup's classic assumption that population pressures inevitably lead to agricultural innovation and intensification so as to elevate food production to feed growing households. Three decades have since passed, and it becomes of great interest to explore and qualify how Boserup's model has stood in the face of modernisation in the country, and in turn, how population and intensification are ultimately shaping rural lives in the Philippines.

This essay will take as its case study the rice village of East Laguna, a "rural" community located south of Laguna de Bay, the country's largest lake.
As will be examined through a reading of the village's demographic history, the process of demographic transformation and adaptation in the village demonstrates several limits to Boserupian modes of growth while at the same time emphasising the role of agency and practicality in determining smallholder outcomes in the face of socio-economic change.

This essay will begin by identifying its key theoretical premise as framed against Netting's concept of the smallholder and Boserup's theory of agricultural intensification. A brief overview of the socio-economic history and situation of East Laguna Village will follow. How demographic change and adaptation in East Laguna Village qualify Boserupian modes of growth will then be examined, after which brief analysis will ultimately seek to explain how smallholders interact with limits to agricultural intensification, and what such interactions might imply for Philippine rural futures. 


\section{NETTING'S CONCEPT OF THE SMALLHOLDER \& BOSERUP'S THEORY OF AGRICULTURAL INTENSIFICATION}

It has long been commonplace to associate agriculture in developing settings with subsistence farming and likewise to perceive resource-poor farmers as totally dependent on their crops for their survival (Hill 1998: 1). While such a predicament may still apply in some settings, the contemporary situation of resource-poor farmers needs to be understood against the backdrop of constant social change and dynamic adaptation. Framing Filipino agriculturalists according to Robert Netting's (1993) concept of the "smallholder" is particularly appropriate.

Netting defines smallholders as "rural cultivators practicing intensive, permanent, diversified agriculture on relatively small farms in areas of dense population," (Netting 1993: 2). His concept suggests that smallholders have the family household as the major corporate social unit responsible for mobilising agricultural labour, managing productive resources, and organising consumption. Smallholders produce a significant part of their household's subsistence by participating in the market to sell some of their agricultural goods while also carrying on cottage industries or other off-farm employment for added income (Netting 1993: 2). Worth noting also are the following key traits which Netting emphasises as facilitating for the enduring social and economic nature of smallholders:

- they are members of communities with common property and of established institutions for sharing, monitoring, and protecting resources;

- they have ownership or well-defined tenure rights over heritable land; and

- they make daily decisions regarding the allocation of time and effort, tools, land, and capital in the context of changing climates, resource availability, and fluctuating markets (Netting 1993: 2-3).

Indeed, in response to the historical stereotyping of smallholders as backward and socio-politically inert, Netting considers the survival (and success) of smallholders as due in great part to their wealth of social relationships and their tendency to frame everyday situations and decisions in rationalistic and utilitarian terms. With smallholder practicality and versatility in mind, it then follows that smallholders are assumed to be capable of perpetuating themselves into the future even under stressed circumstances. Such an assumption begs the question-how do smallholders adapt to increasing population pressures and declining resources, given that both greatly constrain the ability of smallholders to continue subsisting on the land which, in turn, provides their purpose and survival? Ester Boserup's attempt to address the same question had resulted in the formulation of her now classic theory of agricultural intensification.

Boserup's theory of agricultural intensification is essentially premised on the assumption that population growth induces a need for increased food production so as to satisfy a growing population (Boserup 1965). In this way, intensification functions to increase not only the amount of food produced from a limited area, but also the predictability of an area's food supply (Darity 1980). The following sequence describes the augmentative process of agricultural intensification as suggested by Boserup (in Darity 1980: 139 and Stone 2002: 330)

1) Where a human population is unable to move out of its existing niche and into areas of richer resources (as in shifting cultivation), rising population density and land scarcity in the same land-base would necessarily require fallow periods to shorten and food production to rise so as to ensure adequate yields.

2) As a result of more intense land-use, plots are likely to become increasingly less fertile.

3) Mandates are then created to expand human efforts for better field preparation, fertilisation, irrigation, and weed control.

4) Such mandates would necessarily lead to a rise in marginal labour costs, which in turn, induce agricultural innovation and the adoption of improved technology so as to facilitate better returns.

5) Increased food production is realised, and population growth is supported temporarily.

6) The renewed experience of population density and land scarcity would once again spur a need for greater intensification and further innovation.

Boserup also notes that agricultural innovation is closely associated with the type of intensification undertaken. She identifies two types of agricultural intensification: 
- Capital-based intensification-referring to investments into labourers, machinery, fertilisers, and/or improved crop varieties; and

- Infrastructure or "landesque"-based intensification-referring to investments into on-site structures such as terraces, irrigation canals, ridged paddies, etc (Stone 2002: 331).

In sum, agricultural intensification via innovation and technology serve to enhance and extend food production beyond normal cropping cycles, where Boserup implicitly argues that intensification and its associated growth can be supported indefinitely for as long as capital and infrastructure-related inputs are maintained (Stone 2002: 330).

Both Netting's concept of the smallholder and Boserup's theory of agricultural intensification raise important propositions about smallholder situations and behaviour. Thanks to the work of Hayami and Kikuchi (2000), a comprehensive set of demographic data is available for East Laguna Village against which these propositions can be tested. The next sections of this essay will now explore the following case-study questions: to what extent can the smallholder-Boserupian growth model explain demographic and agrarian change in East Laguna Village? Are there limits to Boserupian modes of growth?

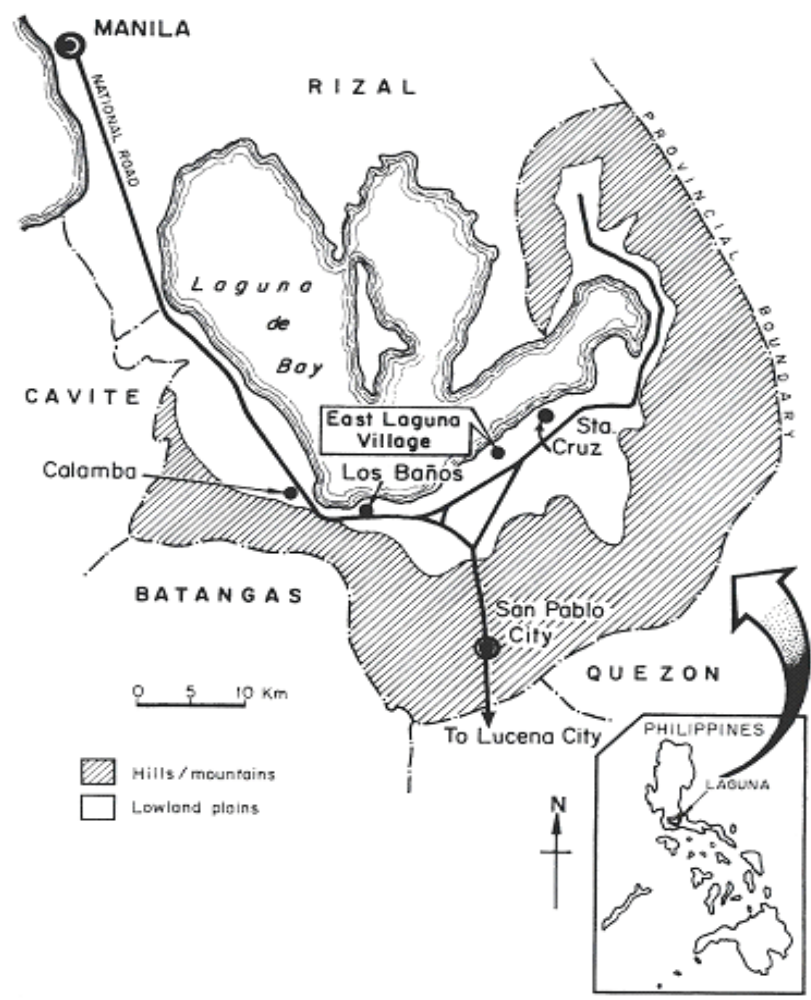

Fig. 1: Laguna Province: referring to area within the provincial boundary (Hayami and Kikuchi 2000: 3).

\section{EAST LAGUNA VILLAGE: A BRIEF OVERVIEW}

East Laguna Village (ELV) lies along the southern coast of the country's largest lake, Laguna de Bay, some 50 kilometres south of Manila (Fig. 1). Unlike the rapidly urbanising west coast, ELV maintains its traditional position as a "rural village" because the strip of irrigated lowland along which the village is situated in has historically been one of the most productive rice-growing areas in the country (Hayami and Kikuchi 2000: 3). Such recognition is also due in part to the fact that prior to the Green Revolution, ELV had a primarily farm-oriented population with $70 \%$ of its economically-active inhabitants engaging in farm activities (Hayami and Kikuchi 2000: 54).

As there is little difference in the elevation between the rice fields and Laguna de Bay, wet rice fields are abundant in ELV and are often flooded during the rainy season. Villagers live on slightly higher ground in thatched roofed houses hidden under coconut groves. Since 1996, a local primary school and a small Catholic church have been operating at the centre of the village (Fig. 2). As of 1997, the village held 266 households and had a population of 1,209 (Hayami and Kikuchi 2000: 3-5).

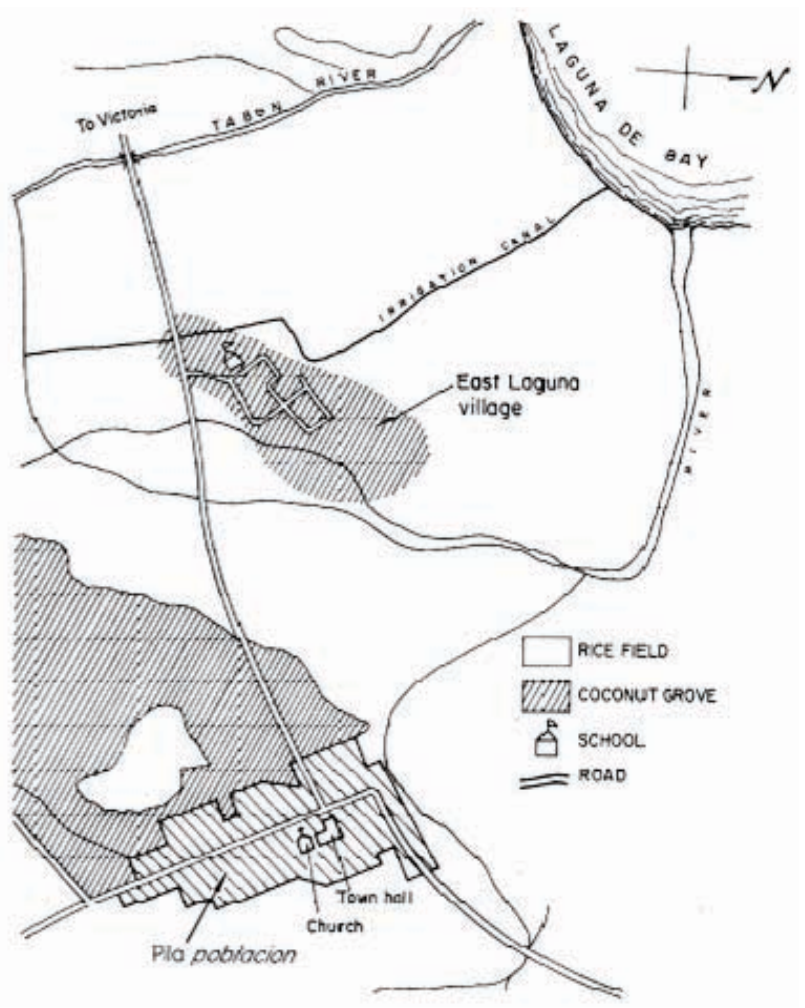

Fig. 2: Map of East Laguna (Hayami and Kikuchi 2000: 4) 
Pila, the closest poblacion or urban municipality, is located 3 kilometres southeast of ELV. Pila was developed during the early Spanish period $\left(16^{\text {th }}\right.$ Century) but is thought to have been a coastal settlement before Spanish colonisation. As the coastline of Laguna de Bay receded, it is presumed that population and resource pressures on Pila and surrounding elevated areas would have influenced the establishment of rice-cultivating settlements on the newly-emerged marshes by the coastline. ELV is speculated to have originated from this phenomenon (Hayami and Kikuchi 2000: 23-24).

From Pila, Spanish landlords established legal claims over ELV, and subdivided its lands progressively through inheritance. During the first several years of "land opening", neighbouring communities as well as locals already living in ELV were enticed by legal landowners to manage their property via sharecropping agreements. Under such an agreement, an absentee landlord provided the necessary capital needed for a tenant to set-up, operate, and maintain a rice farm on the property. Without any formal documentation, the tenant's family was also allowed to build a home on the paddock and to raise poultry and vegetables for household consumption. In return, $50 \%$ of seasonal yields were surrendered to the landowner at the end of harvest time (Hayami and Kikuchi 2000: 24-25). Sharecropping would remain the norm in Philippine agriculture until the 1970 agrarian reforms.

\section{AGRICULTURAL INTENSIFICATION IN EAST LAGUNA VILLAGE : MAJOR DEVELOPMENTS 1950-1997}

The closure of the Laguna land frontier in the early 1950s shifted the momentum of economic growth in ELV from a focus on land expansion to a focus on increasing land productivity (Hayami and Kikuchi 2000: 27)-conditions which, as Boserup argued, make agricultural intensification the logical next step. On the surface, it would seem intensification in ELV took on the form of modern rice varieties, infrastructure and technological improvements, and the transfer of wealth from landowners to tenants.

\section{Introduction of modern varieties, technology, and infrastructure}

Prior to the Green Revolution, rice yield per season in ELV matched the national average of 2-3 tonnes per hectare. This doubled to 4-5 tonnes per hectare with the introduction of modern rice varieties (MVs) to ELV in 1966 (Hayami and Kikuchi 2000: 31). It is to be noted, however, that the introduction of MVs - specifically the landmark IR8 variety - to the village was spearheaded by the International Rice Research Institute (IRRI), located in Los Banos a few kilometeres west of ELV. In this case, ELV was chosen (for logistical convenience and appropriate agroecology) by IRRI to be the first community in the world to test IR8 (Hayami and Kikuchi 2000: 33). This particular agricultural innovation, therefore, had come from outside ELV and not from within, materialising regardless of preexisting population and agricultural regimes.

An irrigation system was set-up in 1958 by the national government which irrigated 4000 hectares of paddy fields and allowed ELV to shift from rainfed farming to complete double cropping (Hayami and Kikuchi 2000: 27). Straight row planting and regulated paddy draining were then locally implemented alongside the use of rotary weeders, threshers, hand tractors, and the intensified application of fertilisers (Hayami and Kikuchi 2000: 30) - all of which demonstrated forms of capital and infrastructure-based intensification leading to enhanced farm productivity and returns.

A country road to Pila was established in 1965; while in 1978, a major highway was created linking Manila to Laguna and to ELV. In 1967, an elementary school was built to provide up to $4^{\text {th }}$ grade education, extending to $6^{\text {th }}$ grade in 1995 (Hayami and Kikuchi 2000: 27, 41).

\section{Land reform}

In an attempt to enhance the benefits of the Green Revolution and promote the diffusion of new rice technologies (such as MVs, chemical fertilisers, and machinery), a major land reform program, initiated under the Marcos government, sought to undermine the position and power of elite absentee landlords. From 1973, shared tenancy (sharecropping) arrangements were formally required to convert to leasehold tenancy, whereby former share tenants would now legally "own" the plot of land they cultivate and be free of any obligation to landlords for as long as a uniform rent rate was paid (Hayami and Kikuchi 2000: 34). Under this new regulation, rent was fixed at a lower rate of $25 \%$ of seasonal yields, with some credit being made available through local extension units. For a period of time, the land reform program was able to transfer landholder wealth to tenants, ease the financial situation of some farmers, and channel farmer credit 
for purchase of modern agricultural inputs supporting intensification (Hayami and Kikuchi 2000: 35). However, with the collapse of the credit system as a result of very low repayments, farmers were left with the sole responsibility and burden of purchasing all their inputs (Hayami and Kikuchi 2000: 99). ELV was no exception in respect to the experience of land reform.

\section{DEMOGRAPHIC TRANSFORMATION AND ADAPTATION IN EAST LAGUNA VILLAGE}

Agricultural intensification and its associated developments had therefore set ELV upon a path towards rapid modernisation, where change, development and how both influenced for demographic transformation and adaptation in the village can be broken down into three themes:

1) Continued population pressure on declining land resources;

2) Land reform and its role in deepening class segmentation;

3) Infrastructure, migration, and alternative livelihoods.

\section{Continued population pressure on declining land resources}

Despite the closure of the cultivation frontier before 1960, the population of ELV increased by as much as 3.7\% per year from 1966 (MVs introduced) to 1997 , well above the national rate of $2.7 \%$ (Table 1) (Hayami and Kikuchi 2000: 47). This extraordinary growth in ELV can be attributed to high rates of natural increase and to extraordinarily high net immigration - an issue which will be tackled shortly.

With high population growth, the availability of rice fields per capita in ELV decreased rapidly, from about a quarter of a hectare in 1966 to less than a tenth of a hectare in 1995 (Hayami and Kikuchi 2000: 14). The increase in crop area and rice yields through the years as a result of irrigation, MVs, and other agricultural innovations had no power to prevent population and resource pressures from increasing landlessness in the village. This problem of landlessness in ELV is demonstrated by the dynamic shown on Table 2 (see next page), where an increasing proportion of the economically-active population (13-65+ years old) are having, and would have in the future, less or no cultivable land to inherit and subsist on. Indeed, land scarcity is clearly reflected by the sudden drop in the proportion of farmers' households from $70 \%$ to $15 \%$ during the period of 1966-1997, and by the increase in proportion of agricultural labourers' (landless) households from $30 \%$ to $60 \%$ (Table 3) (Hayami and Kikuchi 2000: 54)_changes, which shall be discussed, were as much facilitated by land reform.

Though ELV can be considered as undergoing demographic transition-demonstrated by the gradual decline in birth rates and the stabilisation of death rates - it is arguable that agricultural intensification and its associated developments have limited, if not fallen behind in, the provision of adequate agricultural resources across the village's population. This is particularly demonstrated by how ELV's land-base continues to decline and how rice farming is becoming less accessible and profitable for younger generations.

\section{Land reform and its role in deepening class segmentation}

Before land reform took place in the 1970s, two recognisable class groups existed in ELV - that of landowners and leaseholders (Hayami and Kikuchi

\begin{tabular}{|c|c|c|c|c|c|c|c|}
\hline & \multicolumn{3}{|c|}{ Natural Increase } & \multicolumn{3}{|c|}{ Social Increase } & \multirow{2}{*}{$\begin{array}{c}\text { Total } \\
\text { population } \\
\text { growth } \\
\end{array}$} \\
\hline & Birth & Death & Net & In & Out & Net & \\
\hline $1918-40$ & 4.6 & 2.4 & $2.2(44)^{\mathrm{a}}$ & 3.2 & 0.4 & $2.8(56)$ & $5.0(100)$ \\
\hline $1940-60$ & 5.2 & 1.4 & $3.8(86)$ & 1.9 & 1.3 & $0.6(14)$ & $4.4(100)$ \\
\hline $1960-70$ & 4.7 & 1.4 & $3.3(79)$ & 2 & 1.1 & $0.9(21)$ & $4.2(100)$ \\
\hline $1970-80$ & 4.6 & 0.8 & $3.8(83)$ & 3.5 & 2.8 & $0.7(17)$ & $4.5(100)$ \\
\hline $1980-90$ & 3.1 & 0.7 & $2.4(74)$ & 4.2 & 3.4 & $0.8(26)$ & $3.2(100)$ \\
\hline $1990-97$ & 2.6 & 0.6 & $2.0(60)$ & 5.2 & 3.8 & $1.4(40)$ & $3.4(100)$ \\
\hline $1918-97$ & 4.4 & 1.5 & $2.9(68)$ & 3.1 & 1.7 & $1.4(32)$ & $4.3(100)$ \\
\hline
\end{tabular}

Note: ${ }^{a}$ Percentages to totals are in parenthesis

Table 1: Birth, death, and migration rates in ELV, 1918-1997 (Hayami and Kikuchi 2000: 49) 
2000: 24-25). The implementation of land reform raised expectations that the distribution of wealth away from landlords and towards village smallholders would establish a fairly equitable class system whereby farmers thrived and a portion of the village's educated, non-farm workers participated in alternative livelihoods (Hayami and Kikuchi 2000: 78). However, with the failure of land reform, demographic transformation in ELV materialised in a wholly different manner.

Firstly, the failure of the local credit system made it extremely difficult for a majority of farmers to absorb the costs of intensification, despite land reform granting the farming sector considerable autonomy. This led to the polarisation of the farm community in ELV, where on one side of the spectrum were the large farmers who, as a result of the initial effects of lowered rent rates, prospered and could afford to purchase and maintain two or more hectares of farmland. While on the other end of the spectrum were the small farmers who, as a result of not being able to keep up with operational costs and market pressures, were forced to sell part of their land, or more commonly, move out of farming (Hayami and Kikuchi 2000: 57, 83).

Whereas prior to land reform, ELV ensured through the hunusan mode of income sharing that farmers falling on hard times and landless labourers were provided with work on a neighbour's plot in exchange for one-sixth of the harvest, market pressures and an awareness of relatively low wage rate standards from urban areas served to undermine this social mechanism and therefore cut opportunities for farmers to bounce back from economic ruin (Hayami and Kikuchi 2000: 36).

Added to the increasing landlessness, the inability of most households to intensify farm operations substantially led 2000: 52) to the emergence of a new social class of landless agricultural labourers. As mentioned earlier, agricultural labourers' households increased from $30 \%$ to $60 \%$ during $1966-1997$ (Table 3), indicating not only declining land availability and farm opportunities but also a growing young and unskilled labour force desperate for any form of work.

It also goes without saying that the income disparity in ELV has become worse since the reforms, with large farmers in 1995 earning $56 \%$ of the village's income and owning a startling $99 \%$ of the village's share of land-indicating that most, if
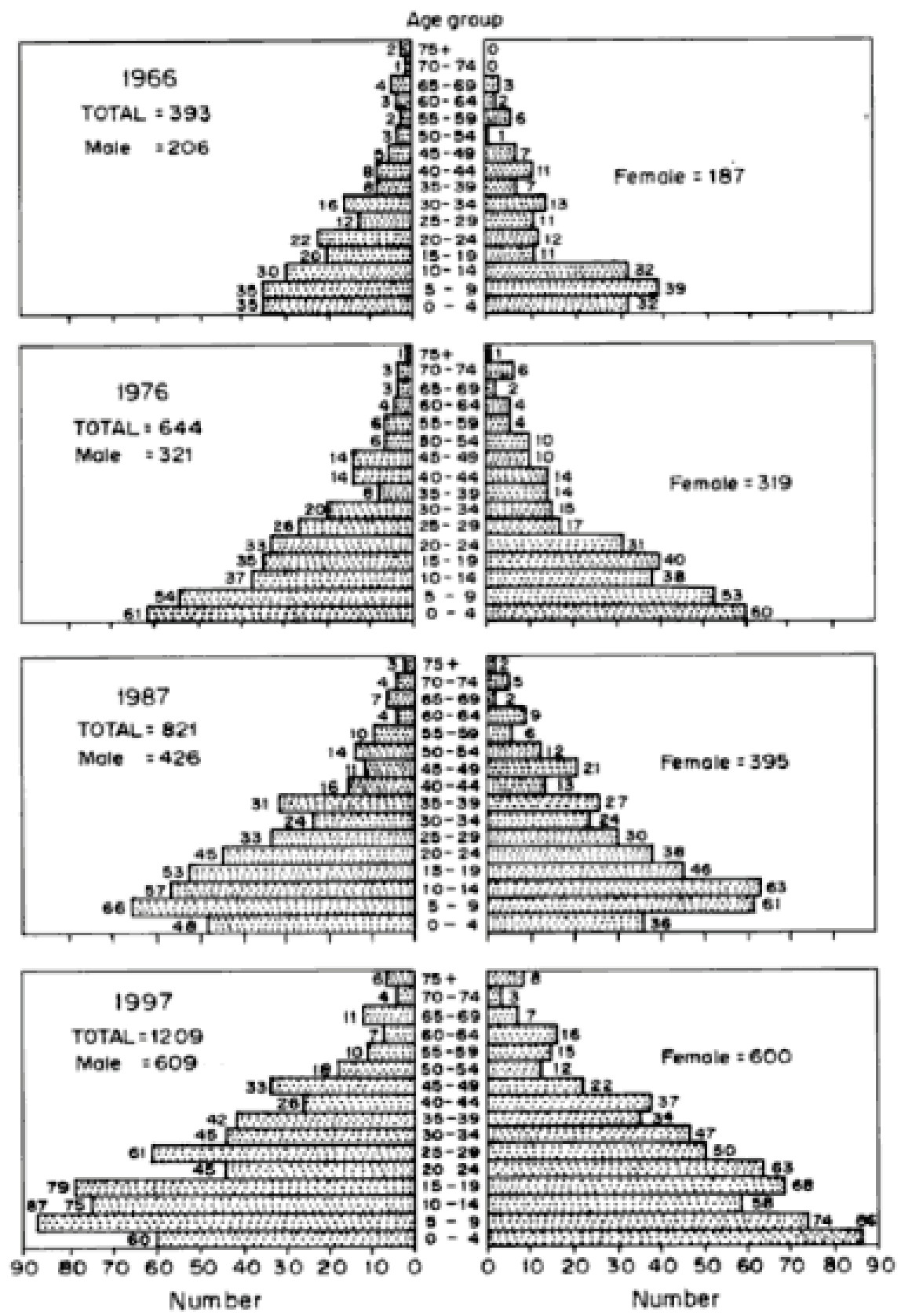

Table 2: Age distribution in ELV, 1966-1997 (Hayami and Kikuchi 
not all, of the remaining farming households in ELV are composed of ELV's elite (Hayami and Kikuchi 2000: 242).

\section{Infrastructure, migration, and alternative livelihoods}

The high costs of agricultural intensification coupled with the effects of land reform seem to have favoured a form of demographic transformation in ELV whereby smallholders were left with little choice but to veer away from land as the primary source of subsistence. Indeed, if it were not for developments outside agriculture, smallholders in ELV would truly be struggling to make ends meet.

The construction of paved roads linking Pila, Laguna, and Manila to ELV, together with the extension of the local elementary school, proved central to adaptive trends in the village. Since the

\begin{tabular}{ccccc} 
Year & Farmer $^{\mathbf{a}}$ & $\begin{array}{c}\text { Agricultural } \\
\text { labourer }^{\mathrm{b}}\end{array}$ & $\begin{array}{c}\text { Non-farm } \\
\text { worker }^{\mathbf{c}}\end{array}$ & Total \\
\hline 1966 & 46 & 20 & 0 & 66 \\
& $(170)^{\mathrm{d}}$ & $(30)$ & $(0)$ & $(100)$ \\
1974 & 54 & 41 & 0 & 95 \\
& $(57)$ & $(43)$ & $(0)$ & $(100)$ \\
1976 & 54 & 55 & 0 & 109 \\
& $(50)$ & $(50)$ & $(0)$ & $(100)$ \\
1980 & 46 & 76 & 4 & 126 \\
& $(37)$ & $(60)$ & $(3)$ & $(100)$ \\
1983 & 44 & 76 & 5 & 125 \\
& $(35)$ & $(61)$ & $(4)$ & $(100)$ \\
1987 & 53 & 98 & 7 & 158 \\
& $(34)$ & $(62)$ & $(4)$ & $(100)$ \\
1995 & 51 & 150 & 41 & 242 \\
& $(21)$ & $(62)$ & $(17)$ & $(100)$ \\
1997 & 41 & 163 & 62 & 266 \\
& $(16)$ & $(61)$ & $(23)$ & $(100)$ \\
Growth rate & $\mathbf{( \% / y e a r )}$ & & & \\
$1966-74$ & 2 & 9.4 & $----^{\mathrm{e}}$ & 4.7 \\
$1974-80$ & -2.6 & 10.8 & ---- & 4.1 \\
$1980-3$ & -1.5 & 0 & 7.7 & -0.3 \\
$1983-7$ & 4.8 & 6.6 & 8.8 & 6 \\
$1987-97$ & -2.5 & 5.2 & 24.4 & 5.3 \\
\hline
\end{tabular}

\footnotetext{
Notes:

${ }^{a}$ Households cultivating paddy fields

${ }^{b}$ Households having no land to cultivate and engaging in hired farm work

${ }^{c}$ Households having no land to cultivate and engaging only in non-farm activities

${ }^{d}$ Percentages to totals are shown in parenthesis

e----- stands for data undefined
}

Table 3: Number and percentage of households by type in ELV, 1966-1997 (Hayami and Kikuchi 2000: 54). 1980s, a growing proportion of village households have begun to take advantage of ELV's urban networks and education to seek off-farm employment in most especially Pila. By the early 1990s, migration and higher education (for non-farm work) were seen as the only escape from local hardships and dead-ends (Table 3, see growth rate) (Hayami and Kikuchi 2000: 61).

Teaching, secretarial and accounting work have become particularly popular amongst women in the village. Several male agricultural labourers have also entered contracts as temporary construction workers and craftsmen in Pila, while a small portion of ELV's failed farmers have also found a means for survival as, ironically, agricultural consultants to neighbouring villages (Hayami and Kikuchi 2000: 61). Such adaptive trends seem to have come full circle with the establishment of a metal craftworks industry in the village during the early 1990 s as a result of a villager venturing into Manila and successfully sealing a subcontract with a major metal manufacturing company. This local industry boomed in the 1990s and played a significant role in the growth of ELV's non-farm working population (Hayami and Kikuchi 2000: 41).

The success of the metalworks industry in the 1990s, together with the improvement of infrastructure and cheap housing in ELV, made the village particularly attractive to (worseoff) upland villages whose villagers, since the construction of the irrigation system and the introduction of MVs decades earlier, had already begun emigrating into ELV for similar reasons of population and resource pressures (Hayami and Kikuchi 2000: 64-66). Migration into the village has grown faster through the years than net emigration out of the village (Table 1, social increase). This suggests that, given that most uplanders are of unskilled and uneducated backgrounds, the proportion of agricultural labourers in ELV is only likely to increase as a result of high net immigration. However, with increased market and land pressures, the non-farm section of ELV is also likely to thrive and inspire younger generations to look away from the farm for prosperity. 


\section{CONTEXTUALISING THE SMALlHOLDER IN EAST LAGUNA VILLAGE: LIMITS TO BOSERUPIAN MODES OF GROWTH}

To what extent then can the smallholderBoserupian growth model explain demographic change in ELV? Are there limits to Boserupian modes of growth?

A careful reading of ELV's demographic history leads to the conclusion that, indeed, smallholders and agricultural intensification have undeniably played critical roles in the village's existence and development. However, as suggested by increasing landlessness in the village and the gradual shift in population composition favouring non-farming households in ELV, there is a need to acknowledge limits to Boserupian modes of growth and a need to revise conceptualisations of the smallholder. The following section will attempt to qualify and synthesise the limitations of both theories via ELV's experience of demographic transformation and adaptation.

\section{1) Boserup's theory of agricultural intensification tends to be ahistorical and apolitical}

As mentioned, agricultural intensification in ELV happened alongside land reform and the re-ordering of traditional society-whether the villagers liked it or not. Although agricultural intensification may have brought about increased rice productivity in ELV for a limited time, agricultural growth could not be maintained due to a lack of consistent government support and, more recently, a lack of local political will. Also, it is important to emphasise that the closure of the land frontier and the introduction of MVs, chemical fertilisers, and proper irrigation in ELV - all integral to inducing intensification-were all orchestrated by exogenous entities; where one cannot help but wonder if it had not been for outside influence and imposition, would we still have seen a similar transformation in ELV's demography? ELV's situation therefore demonstrates a need to integrate local history and politics in studying how agricultural intensification might be constrained and regulated by agents other than the smallholder (Stone 2002: 332).

\section{2) Ecological and economic factors set limits to Boserupian growth}

Population growth in ELV reached its peak during the period between 1960 and 1980 (Table 1), the same time agricultural intensification was most fruitful and technological innovations were being zealously and affordably applied by farmers. After 1980, population growth in ELV gradually declined, seemingly demonstrating "demographic transition". This decline in population growth, however, can partly be attributed to two major factors limiting further agricultural intensification in ELV.

Firstly limiting further Boserupian growth in ELV was the decreasing momentum of and returns from technological uptake. The increasing application of fertilisers and herbicides in ELV (which in the 1980s was four times more than in the 1960s), together with the cultivation of more MVs, conversely resulted in declining yields and other land-related problems like salinity and pest attacks (Hayami and Kikuchi 2000: 110-113). What this experience illustrates, therefore, is that agricultural intensification is greatly limited by the ability of an agroecosystem to sustain production (Stone 2002: $331)$.

Secondly, if we were to follow Boserup's line of thinking, the above problems could have been quickly remedied through the application of more inputs for more intensification. However, the failure of land reform in ELV severely undermined the income of farmers and hence reduced their ability to purchase inputs (Hayami and Kikuchi 2000: 122123) - in turn demonstrating that Boserupian growth is significantly constrained by the income of farmers relative to the costs of intensification.

\section{3) Smallholder survival does not necessarily have to rely on agricultural sources}

Returning now to notions of smallholder "practicality" and "versatility", the experience of increasing resource pressures and landlessness in ELV certainly confirms the prominence of both traits in the village, where through the years smallholder adaptation in ELV has tended to move away from "rural cultivation" and "permanent agriculture" as a primary basis for survival. The strong trend favouring off-farm employment amongst the non-elite section of ELV qualifies Netting's original smallholder concept, and suggests that human agency and a desire for a better life amongst rural inhabitants (including former farming families) will almost inevitably shift smallholder attention to livelihoods proven to be more lucrative and accessible - regardless of whether or not such opportunities come from agriculture or promote community values. Indeed, the combination of 
increasing population pressures and decreasing land resources is likely to shift the interests of most especially poor smallholders away from food production and community interests, and towards alternative livelihoods and family interests.

\section{4) Rural-rural migration can lead to further rural population pressures}

While unusual, high net immigration into rural communities can lead to further population and resource pressures. In ELV, the migration of upland migrants into the village has intensified local competition for land and opportunities as these migrant populations add to the growing section of unskilled and landless agricultural labourers in ELV. Also, a constant influx of outside populations into the rural community might systemically upset any equilibrium and/or benefits possibly achieved through intensification or demographic transition in ELV.

\section{CONCLUSION}

If rice farming has truly lost its once central relevance amongst a majority of ELV's population, then it would seem inappropriate to continue imagining ELV as a proper "rural village". Indeed, the experience of change and modernisation through ELV's dynamic demographic history has indubitably transformed the very foundations of its population, increasingly disqualifying the village from conventional "rural" standards. In particular, the experience of landlessness, population pressure, and the growing popularity of off-farm work in ELV begs the question of whether or not it is still sensible for "rural life" to be tied down to "land" and "agriculture".

As this essay has argued, agricultural intensification in the context of the smallholder is far more than just a simple relationship of give and take or of increasing inputs and outputs. There are several limits to Boserupian modes of growth, limits which, coupled with several other political, ecological, and economic factors, compel the smallholder to rethink his/her position in the greater scheme of rural life and rationalistically approach survival in practical terms, even if this means moving away from the land for subsistence. Hence, the process of demographic transformation and adaptation in ELV, together with its lessons, not only provides us with an idea of how long-term socio-economic change is likely to interact with existing rural demographic and social regimes, but simultaneously also helps us appraise the enduring ability of smallholders to come up with appropriate strategies to further perpetuate and improve their existence.

\section{ACKNOWLEDGEMENTS}

The author would like to acknowledge the assistance of Dr. Robert Attenborough in the process of editing this article.

\section{REFERENCES}

Boserup, E., 1965. The Conditions of Agricultural Growth: The Economics of Agrarian Change under Population Pressure, Chicago, Aldine.

Darity, W. (1980). The Boserup Theory of Agricultural Growth, Journal of Development Economics, 7: 137-157.

Hayami, Y. and Kikuchi, M., 2000. A Rice Village Saga: Three Decades of Green Revolution in the Philippines, New York, Barnes \& Noble.

Hill, R.D., 1998. Stasis and Change in Forty Years of Southeast Asian Agriculture, Singapore Journal of Tropical Geography, 19(1): 1-25.
Netting, R., 1993. Smallholders, Householders: Farm Families and the Ecology of Intensive, Sustainable Agriculture, California, Stanford University Press.

Stone, G.D., 2002. Agricultural Change Theory, International Encyclopedia of the Social and Behavioral Sciences, Elsevier Science Ltd.

Van der Eng, P., 2004. Productivity and Comparative Advantage in Rice Agriculture in South-East Asia since 1870, Asian Economic Journal, 18(4): 345-370. 